\title{
Rapid changes in growth, condition, size and age of small pelagic fish in the Mediterranean
}

\author{
Elisabeth Van Beveren ${ }^{1, *}$, Sylvain Bonhommeau ${ }^{1}$, Jean-Marc Fromentin ${ }^{1}$, Jean-Louis Bigot ${ }^{1}$, \\ Jean-Hervé Bourdeix ${ }^{1}$, Pablo Brosset ${ }^{1,2}$, David Roos $^{1}$, Claire Saraux ${ }^{1}$
}

\begin{abstract}
${ }^{1}$ IFREMER (Institut Français de Recherche pour l'Exploitation de la MER), CRH, Research Unit EME (UMR 212), Avenue Jean Monnet, BP171, 34203, Sète Cedex, France

2 Université Montpellier II, Research Unit EME (UMR 212), Avenue Jean Monnet, BP171, 34203, Sète Cedex, France
\end{abstract}

*: Corresponding author : Elisabeth Van Beveren, email address : elisabeth.van.beveren@ifremer.fr

\begin{abstract}
:
Since 2007, the ecosystem of the Gulf of Lions has shifted to a different regime, characterised by a low anchovy (Engraulis encrasicolus) and sardine (Sardina pilchardus) biomass and a remarkably high sprat (Sprattus sprattus) biomass. Surprisingly, the abundance and recruitment of anchovy and sardine remained high. To understand which processes (bottom-up or top-down control, etc.) could have caused this shift, we studied the changes in body condition, growth and size and age of anchovy, sardine and sprat over 1984-1985 and 1992-2012, using data from scientific surveys. The annual age structure of anchovy and sardine was estimated using Bayesian mixture models based on size frequency data with priors on the age-length relationship derived from independent otolith readings. The results indicated periods during which anchovy and sardine were in an average (1992-2004), good (2005-2007) or poor (2008-2012) overall state of condition. For sardine, the shift towards smaller fish observed during these past 4 years was explained by a combination of slower growth and the disappearance of older individuals (ages 2+). Despite the increase in biomass of sprat since 2008, indications were found that sprat was also smaller than in the past. As growth and condition decreased and overexploitation has not been documented or suspected for those three species in this area, we propose that the current decline in sardine and anchovy biomass could be due to qualitative and/or quantitative modifications in the planktonic production (i.e. a bottom-up control) or mass mortalities of adults due to an epidemic disease.
\end{abstract}


Small pelagic fish are a key component of pelagic ecosystems owing to their high overall biomass at a mid-trophic level, which provides an important energy linkage between upper and lower trophic levels, i.e. wasp-waist control (Rice 1995; Cury et al. 2000). Their population dynamics are known to be strongly affected by environmental fluctuations and predator abundance/human induced changes (bottom-up and top-down effects), causing populations to commonly face conspicuous variations in abundance (Checkley et al. 2009). Those fluctuations can have great consequences for both fisheries and the

Recently, an important shift in the small pelagic fish community of the northwestern Mediterranean Sea has been observed. The dominant species, i.e. sardine (Sardina pilchardus) and anchovy (Engraulis encrasicolus), declined in biomass while sprat (Sprattus sprattus) which has been rare for the last two decades increased tremendously in most recent years (Fig 1., Palomera et al. 2007; GFCM 2011). Surprisingly, the abundance (total number of fish) of both anchovy and sardine has remained relatively high (GFCM 2012) and their mean size has dramatically diminished, making these two species less exploitable (GFCM 2011; GFCM 2012). Whereas sprat is of no commercial interest in this region due to its small size, adult anchovy and sardine have a high economic value. When biomass decreased, commercial landings did as well. Between 1992 and 2004 on average 7094t of anchovy and 11467t of sardine were landed per year in this area, while only 2084t and 7967t were on average landed per year over 2005-2010 (Demaneche et al. 2009; GFCM 2012; FAO 2014), generating important socio-economic consequences.

The major drivers for these changes are yet unknown. The yearly ratio of landings to biomass (i.e. a proxy for the exploitation status) of anchovy and sardine is generally lower than 0.2, with the exception of 1993, 2003, 2004 and 2007 for anchovy and 1997, 2000 and 2001 for sardine. For anchovy, this ratio was thus maximal after their biomass decreased, while for sardine this was before a biomass increase took place. Therefore, fisheries alone is an improbable cause of the observed changes (the General Fisheries Commission for the Mediterranean Sea, GFCM, indeed did not document or suspect overexploitation for those two species in this region). However, overexploitation often interacts with environmental changes, possibly promoting an accelerated population decline and hence becoming an important driver (Planque et al. 2010). Also, large fluctuations in small pelagic fish biomass have often been related to environmentally driven changes in recruitment success (Checkley et al. 2009). Intriguingly, based on size at first maturity, high levels of sardine recruitment have been observed in this area during the decline in biomass of those populations, making the recruitment failure hypothesis rather unlikely.

So why does biomass decrease while abundance increases? And which parameters could be used to help identify the possible drivers (alone or combined)? Several hypotheses may explain the alteration in the population ratio of biomass to abundance, whereby one does not necessarily exclude the other. Firstly, fish might grow up more slowly, so that on average they dwindle in size and accordingly reach a lower weight. Secondly, big old fish may to a certain extent have disappeared from the population (through emigration and/or death). Thirdly, a decrease in condition could lead to fish that have a lower weight for a given size. Depending on which hypotheses are valid, alternative processes driving the population changes (e.g. survival vs. reproduction) could be identified as they might for example be pointing towards bottom-up or top-down control of the pelagic ecosystem, or the occurrence of an epidemic disease.

To resolve the posed hypotheses, body condition, growth and size and age structure were investigated. These parameters are frequently considered for fisheries research, but are rarely reported simultaneously over a long-term period for multiple species. According to the Marine Strategy Framework Directive (MFSD), a "healthy" stock is considered to be a 
population within safe biological limits, exhibiting a population age and size distribution that is indicative of a healthy stock (European Commission 2008). So far no description could be provided as how a healthy age and size structure should be like and for management purposes other parameters have been suggested (Brunel and Piet 2013). However, knowledge on the age and size structure still contributes to the comprehension of how populations fluctuate and the awareness of their condition. In addition to these two variables, we also studied two commonly used population features: condition and growth. Condition factors (such as Fulton's index; Ricker 1975 and Le Cren's relative condition index; Le Cren 1951) are commonly considered to be closely related to fitness, determining the survival and reproductive capacity of individuals (Jakob et al. 1996). They are calculated on length-weight relationships and are convenient to compare the physiological status of fish, assuming that this depends on their relative weight (Froese 2006). On-going research on anchovy and sardine in the Gulf of Lions already confirmed that the relative condition index is correlated to the fat content (P. Brosset pers. comm.). Although body condition and growth are both based on the length of individuals, they provide different information and do not always fluctuate in parallel (Sinovčić et al. 2008).

In this study, we investigated the changes in these key biological population parameters to see if a decrease in biomass cooccurred with a decrease in fish condition or size, which might be the result of slower growing or younger individuals. To do so, we examined acoustic and scientific trawl data from the Gulf of Lions over a period of 21 consecutive years (1992 2012) and two earlier exploratory years (1984 and 1985), and used innovative Bayesian mixture models to get accurate age compositions. By characterizing condition, growth and age and size structure, the state of the population can be investigated, after which the importance of possible mechanisms explaining the observed shift (e.g. environmental factors, competition, disease) can been discussed.

\section{Material and methods}

\section{Data collection}

The Gulf of Lions is a continental margin in the northwestern Mediterranean Sea, covering about $20400 \mathrm{~km}^{2}$. In this area, yearly standardised acoustic and trawl surveys of small pelagic fish (PELMED, "PELagiques MEDiterranée") were carried out in 1984 and 1985 and continuously since 1992 on board the research vessels N/O Thalassa (1984-1985) and l'Europe (1992present). Sampling was generally done in July, except in 1984-1985 and 1995, when individuals were caught in August. Data were systematically collected along 9 parallel transects perpendicular to the coastline, 12 nautical miles apart (22km). The vessel navigated at depths between approximately $20 \mathrm{~m}$ to $200 \mathrm{~m}$ (the border of the continental shelf, where the abundance of most small pelagic fish drops critically). When the echosounder detected sufficiently long fish traces ( $\geq 2 \mathrm{~nm}$ ) or a change in the echotrace characteristics, a pelagic trawl was deployed to assess the species composition. The content was sorted and the total weight of every species caught was measured. Anchovy, sardine and sprat were then classified in $0.5 \mathrm{~cm}$ size classes (with their length rounded down), of which the total weight and the fish count were afterwards determined. When the total catch was too large, a random subsample was taken. Over the whole period, the number of trawls made per survey ( $\geq 30 \mathrm{~min}$ at $4 \mathrm{~nm} / \mathrm{h}$ ) varied between 15 and 54 (with the exception of 1984 when only 10 trawls were taken). The protocol of acoustic and trawl surveys to assess pelagic fish stocks was described by Doray (2010) and further details on the sampling methodology can also be found in Plounevez and Champalbert (2000) and Brehmer et al. (2006).

To estimate age from length, otoliths of anchovy and sardine were collected during the period 2002-2012 (as well as in 1993, 1998 and 1999 for anchovy). During the PELMED and June MEDITS surveys (MEDITS working group 2012) individuals were selected for otoliths reading so that the entire size range was covered. Throughout certain years, fishermen were asked to randomly select anchovy $(2006,2009-2012)$ and sardine $(2005,2006,2009-2011)$ caught in the Gulf of Lions from 
June to September, doubling the amount of length-age records for each species. The total length of each individual was measured (to the inferior $0.5 \mathrm{~cm}$ ) before the otoliths (sagittae) were extracted and read.

\section{Data analysis}

\section{Length-weight relationship and body condition}

The condition of the 3 species was compared between years, using weight-length relationships and a relative condition factor (Le Cren 1951). Both analyses are reported in this study because they differ in results and utility. An analysis of covariance (ANCOVA; Zar 1999) was performed so a difference in the year-to-year slopes of the fitted linear relationships $\log (W)=\log (a)+b \cdot \log (L)$ could be detected (were $\mathrm{W}$ is the mean weight of individuals of length $\mathrm{L}$ ). Because we wanted to test for a year-to-year difference, the interaction between the categorical predictor variable (year) and the covariate was included in the full model. This model was superior based on AIC selection and anova tests compared to more parsimonious models with only an additive effect of year and size or with size alone. A Tukey test was then used to investigate the pairwise relationship between all years.

Because length distributions changed on a yearly basis and b was not always equal to 3 (Froese 2006), a relative condition factor (measuring the anomaly in weight of a fish of a given length) was calculated per year and per trawl for each size class:

$K_{r e l}=\frac{W}{a L^{b}}$

where $\mathrm{a}$ and $\mathrm{b}$ are the regression parameters of the length-weight relationship computed over all data pooled together. These length-weight relationships were highly significant for all 3 species $\left(R^{2}>0.95, p<0.001\right)$, with the following allometric formulas: $\mathrm{W}=3.86 \cdot 10^{-3} \cdot \mathrm{L}^{3.20}, \mathrm{~W}=5.90 \cdot 10^{-3} \cdot \mathrm{L}^{3.10}$ and $W=3 \cdot 21 \cdot 10^{-3} \cdot \mathrm{L}^{3.37}$, for anchovy, sardine and sprat, respectively. A Kruskal-Wallis test was used to check for statistical differences in body condition index between years, followed by a multiple comparison post-hoc test. Furthermore, the use of the relative condition factor allowed for a comparison between age groups by attributing an age to each length class, based on the output of the age structure analysis.

\section{Size distribution}

We plotted a size frequency distribution per year per species in order to describe the temporal variations in length structure of the 3 populations. The number of measured fish $(n)$ and the number of trawls from which they originated $(N)$ ranged between 811-6229 ( $\mathrm{N}=5-40), 564-5060(\mathrm{~N}=9-42)$ and 0-5004 $(\mathrm{N}=0-30)$, for anchovy, sardine and sprat, respectively. For sprat, no or very few individuals $(<6)$ were found in 1993, 1998, 1999 and 2001. When only a subsample had been measured, the total frequency of individuals per length class was obtained by weighing the measured frequency of individuals per length class of a trawl by the total species weight in the trawl divided by the subsample weight. Anchovy smaller than $8 \mathrm{~cm}$ were removed from all analyses because they were generally not caught or targeted (except during 1995).

\section{Size at age and growth}

Growth was only considered for anchovy and sardine since no otolith readings were available for sprat. Age-length data from fish caught between June and September were selected, so all factors investigated reflected the status of the populations during summer. To measure growth rates of anchovy and sardine and to construct the age-length priors for the mixture models, 3313 and 2974 otolith readings acquired during the summers of 13 and 11 years were used for anchovy and sardine, respectively. Both species displayed year-to-year variations in length-age relationships that were similar to what was observed for the condition index and median size. Therefore this data was split up into periods, which we 
retained for age structure analyses. For sardine, non-linear least square regression was used to fit a Von Bertalanffy model for each period, using the nls function of $R$ ( $R$ core team 2013):

$L_{t}=L_{\infty}\left(1-e^{-K\left(t-t_{0}\right)}\right)$

where $L_{t}$ is the expected length at age $t, L_{\infty}$ is the asymptotic maximum length, $K$ is the von Bertalanffy growth constant and $t_{0}$ is the theoretical age at length zero. For sardine, too few otolith readings were available per age class per year to fit annual models, especially for the early period. For anchovy, length at age 0 was removed since data was originating from a small number of individuals found during few years. As a result, not enough age classes were present for anchovy to accurately fit a growth model. For sardine, we also calculated the overall growth performance (Pauly and Munro 1984):

$\emptyset^{\prime}=\log _{10} K+2 \log _{10} L_{\infty}$

This enabled us to reduce the number of parameters of the Von Bertalanffy growth model to one, as to compare growth more easily between periods and with previous studies.

\section{Age distribution}

Bayesian mixture models were used to estimate the age structure from both length frequency data and age-length keys. In doing so, a framework was developed that is more powerful than traditional mixture models that are based on only one of these information sources. As the age-length keys used as priors were based on otolith readings, this analysis could only be performed for anchovy and sardine. Priors were constructed based on the extracted summary statistics (mean length, standard deviation, number of data points) of a normal distribution fitted to the length frequency plots of each age class, per species and per period. To do so, size frequency per age class was first weighted by the total frequency of that age to compensate for potential biases in the sampling. The choice for a prior per period (instead of one general prior) allowed us to obtain a more accurate estimation of the age structure. For the years where no data derived from otoliths were available (mostly before 2002), the prior from the period after was used. Since the priors were constructed based on data from more recent years, we considered them to be unreliable for the use of age structure analysis of 1984 and 1985.

The finite mixture model was fitted on the weighted size distributions using Rstan, an R package for Bayesian modelling that uses a variant of the Markov-Chain Monte Carlo sampling technique (Stan Development Team 2013). The model had the following output parameters (per mixture component): $\mu_{\text {age }}$ (mean length at age), $\sigma_{\text {age }}^{2}$ (standard deviation of $\mu$ ) and $\theta_{\text {age }}$ (mixing proportion). The mixing proportion is an estimate of the relative abundance of each age category in relation to the total population. The prior for $\mu_{\text {age }}$ was a normal distribution where $\mu$ and $\sigma^{2}$ were replaced with values from the age-length prior. Age classes were forced to be ascending. Therefore, we truncated the upper limit for $\mu_{\text {age }}$ by the value for $\mu_{\text {age }+1}$ reduced with the minimal distance between two mixture components. This value was calculated as the minimal difference in mean length found between 2 successive age classes from 2 successive years (so a cohort was followed) from individuals used for otolith analysis. For our data, this improved the results significantly as label switching (when within or between chains labels switch between peaks) was avoided, allowing the model to converge (Stephens 2000; Jasra et al. 2005). Furthermore, on the uniform prior for sigma a constraint on the lower and upper limit was set (0.2-2) to avoid extreme values that were highly unlikely from a biological point of view. The starting values for the parameters $\mu_{\text {age }}$ and $\sigma_{\text {age }}^{2}$ were based on the prior, and $\theta_{\text {age }}$ was initiated at $1 / \mathrm{M}$ (with $\mathrm{M}$ being the number of mixture components).

Since a finite mixture model was used, it was necessary to find the optimal number of components (M) to fit. We decided to select $\mathrm{M}$ manually, since $\mathrm{M}$ was impossible to be determined from the data alone (Hunt and Jorgensen 1999; Laslett et al. 2004). Given that the prior indicated the expected mean length and standard deviation of each age class, the estimation of 
the number of components likely to be present was mostly straightforward. Still, each time the model was run for at least 2 different values of M. For each year and species, the model outputs were compared by superimposing them on the observed histogram. Together with convergence assessment, this allowed us to select the optimal $\mathrm{M}$ value and to confirm that the results were biologically plausible.

\section{Relationship with abundance and biomass}

Principal component analyses were used to summarise into a few dimensions (i.e., the principal axes) the variability of the different population parameters (the descriptors) over time (the objects), so that we could comprehensively consider the state of the population during certain periods. Estimates of the total abundance and biomass of anchovy, sardine and sprat in the Gulf of Lions were deduced from acoustic information, except for 1992 and 1994 . We considered the relationship (with and without lag) between abundance and biomass (both log transformed) and the average fish size, body condition (Le Cren's relative condition index) and age (calculated as the sum of all ages multiplied by their relative abundance in the population, i.e. $\theta_{\text {age }}$ from the mixture models). Growth was excluded since data is limited to certain years. Since age information was not available for sprat, we only conducted this analysis on anchovy and sardine.

\section{Results}

\section{Length-weight relationship and body condition}

The ANCOVA established that yearly length-weight relationships differed significantly (anchovy: $F=14.79, p<0.001$, sardine: $F=32.34, p<0.001$, sprat: $F=6.31, p<0.001$; Fig. S1). However, a post-hoc test revealed no apparent grouping of certain years for sardine and sprat. For anchovy, the 3 last years were significantly different from almost all other years as individuals had a lower allometric coefficient ("b"). Although not significant, the graphs for the other 2 species indicated likewise a lower $b$ during these last years. The highest condition was demonstrated to be around 2005-2007 for anchovy and sardine, but again the result was not significant. Regarding these last two points, we cannot conclude if the lack of significance is due to limited information for some years and/or a real absence of contrast between years.

A significant difference between all years was also established for the 3 species in the condition factor $\mathrm{K}_{\text {rel }}$ (Kruskal-Wallis test, $\mathrm{p}<0.05$ ), which ranged from 0.96 to 1.05 for anchovy, from 0.92 to 1.08 for sardine and from 0.96 to 1.22 for sprat (Fig. 2). Because of the few data available for sprat, the standard deviation is relatively high in most years. In contrast to the results from length-weight relationships, the use of Le Cren's $\mathrm{K}_{\text {rel }}$ index led to the grouping of some years, i.e. both anchovy

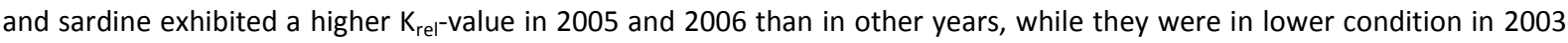
and in 2009-2012. For sprat, those 2 periods were also visible, but they were not significantly different from the earlier years since they were characterised by large fluctuations and standard deviations. Although we only had few data in 1999 and 2000 for sprat, it is of interest to note that the condition factor was high in those years. For anchovy and sardine we found no pronounced discrepancy between the changes in body condition of different age classes, although in 2011 a slight increase in condition of 2 year old sardines was visible (Fig. S2).

\section{Size distribution}

The maximum total length of anchovy observed was $18.5 \mathrm{~cm}$ and $95 \%$ of all individuals had a length between 10.0 and $15.5 \mathrm{~cm}$ (median=12.5cm, Fig. S3). The modes of the mostly unimodal size distributions remained fairly constant until 2005 , whereupon a sudden shift towards larger individuals was detected (Fig. 3). During the following years, a size decline took place, whereby after 4 years the size range reached the same state as before 2005 . The continuation of this decrease caused the median fish size of the anchovy populations of the last 4 years (2009-2012) to be smaller than in all preceding 
years (median=11cm). The size distribution of 1984 and 1985 did not noticeably differ from the early invariable period (1992-2004)

Sardine had a median length of $14.5 \mathrm{~cm}$, with $95 \%$ of all fish having a size between 8.5 and $17.5 \mathrm{~cm}(\mathrm{~min}=5.5 \mathrm{~cm}, \mathrm{max}=22 \mathrm{~cm}$, Fig. S3). In contrast to anchovy, 2 distinct modes were discernible for most years, of which the second (containing the larger individuals) seemed to diminish gradually from 2009 onwards (Fig. 3). When looking at absolute values, it becomes clear that this tendency is not only caused by a decrease in the proportion of larger fish (possibly caused by e.g. an increase in younger fish), but also by their disappearance, as for instance fish larger than $17 \mathrm{~cm}$ were not caught in 2012 , whereas before 2009 this always happened in considerable abundances. From 1992 to 2008 there were some fluctuations in the proportion of individuals belonging to each peak and the mean size of both modes, but no clear trends. During 1984 and 1985, individuals were on average larger than in most other years. These two years were the only ones in which sardines bigger than $21 \mathrm{~cm}$ were found.

The size range of measured sprat was between 5 and $14.5 \mathrm{~cm}$ (median=9.5cm and $Q_{2.5-97.5}=8-12.5$ ). Although in the last years more individuals were sampled, the maximum size observed was still smaller than during previous years in which, however, only few sprat was found (Fig. 3). This period (2008-2012) was mainly characterised by one single peak (except for 2011), while in other years 2 modes were clearly visible (1984-1985, 1996, 2004-2006). Because of the lack of data for some years, it is difficult to detect any clear trend. A comparison between species showed that sprat and sardine displayed larger year-to-year variations in size distribution than anchovy (Fig. 3).

\section{Size at age and growth}

For anchovy and sardine, otoliths of age categories 0-4 and 0-8 were found, with very few individuals belonging to the oldest age classes. Periods with a dissimilar age length relationship were observable; hence the data was split based on visual inspection into years with relatively slower, intermediate or faster growing individuals (Table 1, Fig. 4). For anchovy, such a pattern was less visible because of the few age classes. Notably, the years 2006 and 2007 were characterised by the presence and large size of age 4 anchovy. For sardine, a fast growth rate was distinctive throughout 2006-2008 and a clear decrease was visible during the last 4 years (2009-2012). The asymptotic length found for sardine during the slow growing period is particularly high, as a result of the lack of older individuals and the more linear appearance of the Von Bertalanffy growth curve.

\section{Age distribution}

For most years there was a number of cohorts $(\mathrm{M})$ for which the model gave biologically sound results and all parameters converged. The model did not converge only 3 times out of 46, i.e. for the 2003, 2008 and 2011 size distributions of anchovy that were normally distributed and that could thus not be split into multiple components. All results are summarised in figure 5 .

For anchovy, the total number of age classes estimated with the Bayesian mixture model varied between 2 and 3 . Most years (12 out of 18 ) were typified by only ages 1 and 2, while other years consisted out of a mixture of ages 0 to 3 . During 2009, 2010 and 2012 individuals had in general a lower length at age 1 and 2 (except age 2 anchovy in 2010) and during 2010 and 2012 age 1 was dominant. Age 3 anchovy were only consecutively present between 2005 and 2007, during which age classes 1 (when included) and 2 had a higher mean length (although the standard deviation is relatively high). In 1998 and 2000, age class 3 was incorporated as well but had a lower average size than during the 3 year period. The contribution of each age to the annual population did not follow any clear temporal pattern, so that strong or weak cohorts could hardly be followed (Fig. 5 and S3). 
Sardine exhibited an estimated age structure made up of a combination of ages 0 to 3, with age 4 present only in 1996, 1997, 2001 and 2002 (Fig. 5). All age categories showed large temporal variations, but older age classes fluctuated relatively less. From 2006 to 2008, the average length of almost all age classes (0-3) was visibly higher than during all other years. After this period, an overall downwards trend was visible in mean size, together with a decrease in the proportion of older fish and their progressive loss. That is, from 2009 onwards age 3 became unobservable, followed by age 2 in 2011 (while this age class had previously always been present). We found that in the bimodal size structure of sardine, the first mod is always shaped by age- 0 fish, sporadically supplemented by a smaller proportion of age 1 .

\section{Relationship with abundance and biomass}

The PCA analysis allowed us to objectively define the state of health of the populations during the different years, with years situated in similar situations clustered together. The first and second axis of the PCA encompassed together $82 \%$ (anchovy) and 78\% (sardine) of the total variance. The first axes of both PCAs, which alone summarised respectively $49 \%$ and $59 \%$ of the total variance for anchovy and sardine, opposed condition, age and size to abundance (Fig. 6). The first parameters are more or less bundled together and have similar heavy loadings for axis 1 . Biomass and abundance are slightly related as well, although this is less noticeable for sardine. Axis 1 separated years with larger and older fish in a better condition, such as 2005 and 2006 for anchovy or 2006 for sardine from years of reduced size, age and condition, such as 1999, 2010 and 2011 for anchovy or 2008, 2009, 2010 and 2012 for sardine (Fig. 6). Axis 2, which was predominantly explained by biomass, mostly differentiated years of high biomass (2001 for anchovy and 2004 and 2005 for sardine) against years of low biomass (2007, 2010 and 2011 for anchovy or 1997, 2009, 2010 and 2011 for sardine). Note that years of low biomass did not always imply years of low abundance (such as the years 2009, 2010 and 2011 for sardine). So in this study, 3 periods emerged, with the last period (2008-2012) converging to a low biomass and non-optimal biological population indicators. The other two situations could be interpreted as optimal (2005-2007; best state of all parameters) and the baseline scenario (1992-2004).

\section{Discussion}

This study allowed us to (i) assess the amplitude of inter-annual changes and outline the state of the populations, (ii) develop an advanced method to obtain age structures from length data, (iii) document new biological information on anchovy, sardine and sprat in the Gulf of Lions and (iv) make an hypothesis about the possible drivers of the regime shift. For this, different biological parameters were used that are scarcely reported in parallel and simultaneously for multiple species despite their importance. In our study, these parameters fluctuated during the whole period almost independently from biomass and abundance data, only for sardine we found a weak inverse relation of abundance. Even more, sardine abundance was not highly correlated with sardine biomass, indicating that high numbers of individuals in the ecosystem do not always equal a high biomass (and vice-versa). This study illustrates how looking at changes in biomass alone can be misleading as they might reflect various types of changes in the health of a population. The use of the biological parameters allowed us to define periods in which species were in a relatively good or poor state, which could not have been done with abundance and biomass data alone.

\section{State of the populations}

Body condition, growth and size and age structure varied mostly in parallel for sardine and anchovy (except for condition in 1996). Before 2005, most of the parameters showed little variations, apart from body condition for anchovy in the early 1990s. The years 1984 and 1985 were a bit different in terms of mean length for sardine (larger individuals), but only the size structure and the body condition were considered. For anchovy, there was a sudden shift in the size distribution between 2004 and 2005, which went concurrently with a shift towards older and faster growing individuals with a better 
body condition. The two subsequent years (2006 and 2007) displayed the same features, but with a diminishing tendency. In contrast to anchovy, the period 2005 to 2007 was for sardine less eye-catching since the size distribution did not show such a clear shift and an increased growth and a change in age structure was observed only from 2006 onwards. For both species, this shift was followed by an inversion of the pattern from 2009 onwards, with fish becoming smaller, slower growing and having a relatively weaker body condition. Note that body condition started to decrease before the other parameters (i.e. since 2007) for both sardine and anchovy. Additionally, old sardines disappeared, leading to a multiannual low-grade situation that was not observed before. During the latest years (2008-2012), sprats were also smaller and had an average (but not a good) body condition, despite their increase in abundance and biomass. To evaluate the uniqueness of the observed changes and the utility of the selected parameters, we discuss these separately.

\section{Biological parameters}

Length-weight relationship and body condition

Several length-weight relationships have been given for anchovy, sardine and sprat in the Mediterranean, but in the Gulf of Lions this relationship was as far as we know only published for anchovy by Campillo (1992) and calculable for sardine based on the data given by Lee $\left(1961, W=33.70 \cdot 10^{-3} \cdot L^{2.48}\right)$. Essentially, the established length-weight-relationships were useful for obtaining the relative condition factor (as was previously done for these species; see Millán 1999; Sinovčić et al. 2008; Pešić et al. 2010), which in this study proved to be giving more clear-cut results and allowed straightforward inter-species and inter-annual comparisons. That is, distinct periods during which species were in a relatively good (e.g. 2005-2006 for all three species), average (most years preceding 2005) or poor condition (2010-2012 for anchovy and sardine) were most easily defined. Data from Lee (1961) also allowed us to obtain the relative condition factor for sardine in 1959 (1.015). Thus, their condition was probably only slightly higher than average and in the range found for 1984 and 1985.

\section{Size distribution}

Size structures had not been documented for pelagic species in the Gulf of Lions, with the exception of landing-based surveys for sardine in 1959 (Lee 1961) and sprat in February and April 1945 (Furnestin 1948). In spite of fisheries selectivity causing a difference between landing based and scientific trawl surveys and hence bringing forth unimodal size distributions in these two previous studies, the second mode (with the largest individuals) can still be compared. In July 1959, the largest proportions of sardine (>95\%) ranged between 15 and $17 \mathrm{~cm}$, which is similar to the size of the second mode of several years we investigated $(1984,1985,2006$ and 2007). While comparison of the first mode of small sardines is prevented, it highlights once more the anomaly of the gradual disappearance of this second mode since 2009. Similarly, in 1945 , mostly sprat of $11 \mathrm{~cm}$ was caught in the Gulf of Lions, which only happened occasionally from 2009 onwards (Furnestin 1948). Sprat in the Baltic Sea is known to have a bimodal structure similar to our findings for 1984 and 1985, i.e., a first mode (comprising the small individuals) and a second much larger peak (Cardinale et al. 2003). This study revealed that although the sprat biomass has considerably increased, the absence of the second mode in most recent years and a body condition factor close to 1 suggest that sprat is probably not in its best "state of health", in contrast to what could have been expected. For anchovy, the unimodal size distribution observed corresponds to what was previously seen in other regions (Barange et al. 2005).

Size at age and growth

Growth values for sardine showed no remarkable deviation from other regions, except for the last four years which exhibited slower growth rates (Morales-Nin and Pertierra 1990; Voulgaridou and Stergiou 2003; Kada et al. 2010). Growth parameters given for the Gulf of Lions (when sampling was done during the spring, summer or autumn of 7 years; Alemany 
and Álvarez 1993) matched those of the fast growing period. This indicates that this fast growing period is probably not exceptional, and that similar fluctuations might have occurred just before the period of our study. Nonetheless, in Alemany and Alvarez (1993), the actual age of individuals was calculated as the age read plus the year fraction between the survey date and a theoretical birthdate, as to correct for the different sampling periods. Since sardine has a prolonged spawning period, their birthdate is not fixed, possibly leading to different age estimates. For anchovy, length at age in the area was previously given by Campillo (1992), who found values of length at age 1 and 2 most similar to what we found for the slow growing period.

\section{Age distribution}

To test the hypothesis that fish were smaller because they were younger, age structure information was needed. We are to our knowledge the first to combine multimodal decomposition of fish population size structures with otolith readings (agelength priors) within a Bayesian framework. Multiple programs and packages built on mixture models have been developed which can be used for (or are created exclusively for) detecting age classes (e.g. NORMSEP, Tomlinson 1971; mixdist, Macdonald and Du 2012; mclust, Fraley et al. 2013; flexmix, Grün and Leisch 2013). However, they are usually likelihoodbased and do not include systematic prior information, which makes them less efficient at distinguishing the age composition in length-frequency data that does not display clear modes. Software with a Bayesian perspective on mixture modelling (such as bayesf for matlab, Frühwirth-Schnatter 2008) is less available and is not always appropriate for the envisioned analyses (e.g. developed for another research field, limited flexibility, etc.).

The mixture model that we used provided consistent results, despite the absence of several observable peaks in the size frequency data. Only in the few cases where the size distribution resembled a nearly perfect normal distribution did the model not converge. Fish for otolith readings were not randomly sampled but an effort was made during the PELMED surveys to include the largest and smallest individuals, thus enlarging the probability of selecting the oldest and youngest fish. Therefore, older individuals were found in the otolith dataset than were included in the mixture model (age 4+ for anchovy and ages $5+$ for sardine). These age categories were present in certain years, but were too low in proportion (< $0.5 \%$ and $0.1 \%$ for anchovy and sardine, respectively) to be included in the mixture analyses. Furthermore, age 0 was not detected in multiple anchovy size distributions, but this does not imply the absence of this age category at that moment. These youngest individuals were most likely too small to be caught in sufficient numbers by the trawl. In contrast, age 0 sardine were caught in considerable quantities. This discrepancy was probably caused by different spawning seasons (autumn/winter vs. spring/summer for sardine and anchovy, respectively, Palomera et al. 2007; Tugores et al. 2010), making age 0 sardine more prone to PELMED surveys in July.

The life span of anchovy (age 0-4 with age 4 only occurring in extremely small percentages) corresponds to what was found in several other parts of the Mediterranean (Morales-Nin and Pertierra 1990; Bacha and Amara 2012) and earlier in the Gulf of Lions (Campillo 1992). Other studies reported a life expectancy of 3 (Basilone et al. 2004) to 5 years in the Atlantic (Uriarte et al. 1996), but all concluded that only a minor fraction belongs to these oldest age classes. Correspondingly, age 4 was completely lacking from the age distribution of anchovy, which was clearly dominated by ages 1 and 2 . The importance in terms of relative abundance of these two age classes was also observed in the strait of Sicily (Basilone et al. 2004) and the western coast of Algeria (Bacha and Amara 2012). The authors also noted the potential quantitative underestimation of age 0 anchovy. In the Mediterranean, sardine was aged up to 8 years (in agreement with the otolith readings in this paper), but age distributions were not reported afterwards (Pertierra and Morales-Nin 1989; Morales-Nin and Pertierra 1990; Alemany and Álvarez 1993; Kada et al. 2010). In contrast to anchovy, we found a high proportion of age 0 for sardine, and generally a somewhat lower proportion of age 1 fish, but age proportions varied vastly between years. For both species, we 
were unable to follow cohorts over time, indicating that there might be a certain degree of emigration/immigration or agespecific selectivity of the fishing gear (GFCM 2011).

\section{Implications}

The four biological parameters (body condition, size distribution, growth and age distribution) gave additional information on the population fluctuations and general "state of health" of the three stocks investigated that could not have been obtained when investigating these factors and stocks separately. For example, by comparing trends in three species, we were able to infer the scale at which the changes took place. The similarity between the patterns allows us to conclude that the main drivers are unlikely to be species specific. This information could not have been inferred from biomass or abundance data, which fluctuated differently from the studied parameters. The complex relationship between both types of parameters (quantitative vs. biological) delivers an additional stimulus to implement indices of population structure and dynamics when assessing a population's status. Overall, our results confirm that the decline in the anchovy and sardine biomass is most likely not related to recruitment but could be due to the combined effects of poor condition, slower growth and the disappearance of older and larger individuals. This is especially surprising for short-lived species, of which biomass fluctuations are known to be mainly influenced by reproductive success rather than adult survival (see for instance Oli and Dobson 2003; Stahl and Oli 2006). During the studied period, the last years were the only period during which a simultaneous decrease in all four parameters was observed. Moreover, previous research that focussed on small pelagic species of the Gulf of Lions indicated that this simultaneous decline in condition may be a unique occurrence during the last decades (Lee 1961; Lee and Juge 1965).

Possible mechanisms causing such an anomaly can be related to human pressure (fishing) or environmental changes (Sinclair and lles 1989; Agostini and Bakun 2002; Bakun 2010). Because of the preceding exploitation levels (ratio landings/biomass) of the three main species (maximal when their biomass was already low or started to increase) and the nature of the observed changes (e.g. almost parallel for anchovy, sardine and sprat; the latter being not exploited), overexploitation is unlikely to be the prime force of this pelagic ecosystem shift. Furthermore, during the last years the size structure of the landings is also skewed towards small individuals. Thus, the removal of large individuals by fisheries is only occurring to a very minor extent. This does however not exclude fisheries as a possible agent of change, as fishing and other factors can have a joint effect. Since growth and condition are affected, we suggest bottom-up processes (e.g. prey availability and composition) as the main hypothesis. For example, environmental factors might influence the productivity and the quality of the plankton community, possibly favouring sprats, which are known to have a more diversified diet than anchovy and sardine (Banaru pers. comm.). Such environmentally driven changes in small pelagics habitats have already been observed in various ecosystems (e.g. Barange et al. 2009). However, we do not rule out the possibility of an epidemic disease, which could also alter the age and size structure of small pelagics fish, as observed in this study. The risk of infection is estimated to be increased worldwide (Harvell et al. 1999) and previous examples of disease outbreaks drastically affecting small pelagic fish populations exist (e.g. Sardinops sagax in Australia, Jones et al. 1997). Future studies investigating the influence of environmental factors or density dependence on population fluctuations and the presence of pathogens in adult fish should help distinguishing among these 2 main hypotheses.

\section{Acknowledgements}

We thank the captain and the crew of the RV "L'Europe" and RV "Thalassa" as well as all the scientists on board for their assistance during the PELMED surveys. We thank the two anonymous reviewers for their careful review of the manuscript and their excellent suggestions. PELMED surveys are cofinanced by Europe through the Data Collection Framework. We also thank the MEDITS team and the fishermen working with "contrats bleus" to provide us with samples for otolith analyses. 

Pêche (FFP). 


\section{References}

Agostini VN, Bakun A (2002) 'Ocean triads' in the Mediterranean Sea: physical mechanisms potentially structuring reproductive habitat suitability (with example application to European anchovy, Engraulis encrasicolus). Fish Ocean 11:129142. doi: 10.1046/j.1365-2419.2002.00201.x

Alemany F, Álvarez F (1993) Growth differences among sardine (Sardina pilchardus Walb.) populations in Western Mediterranean. Sci Mar 57:229-234.

Bacha M, Amara R (2012) Inter-cohort differences in growth, condition and feeding of juvenile anchovy (Engraulis encrasicolus) in the Gulf of Béjaia (Algerian coast, SW Mediterranean): Implications for recruitment success. Fish Res 129130:73-81. doi: 10.1016/j.fishres.2012.06.012

Bakun A (2010) Linking climate to population variability in marine ecosystems characterized by non-simple dynamics: Conceptual templates and schematic constructs. J Mar Syst 79:361-373. doi: 10.1016/j.jmarsys.2008.12.008

Barange M, Coetzee J, Takasuka A, et al. (2009) Habitat expansion and contraction in anchovy and sardine populations. Prog Ocean 83:251-260. doi: 10.1016/j.pocean.2009.07.027

Barange M, Coetzee JC, Twatwa NM (2005) Strategies of space occupation by anchovy and sardine in the southern Benguela: the role of stock size and intra-species competition. Ices J Mar Sci J Cons 62:645-654. doi: 10.1016/j.icesjms.2004.12.019

Basilone G, Guisande C, Patti B, et al. (2004) Linking habitat conditions and growth in the European anchovy (Engraulis encrasicolus). Fish Res 68:9-19. doi: 10.1016/j.fishres.2004.02.012

Brehmer P, Guillard J, Guennegan Y, et al. (2006) Evidence of a variable "unsampled" pelagic fish biomass in shallow water $(<20 \mathrm{~m})$ : the case of the Gulf of Lion. Ices J Mar Sci 63:444-451. doi: 10.1016/j.icesjms.2005.10.016

Brunel T, Piet GJ (2013) Is age structure a relevant criterion for the health of fish stocks? Ices J Mar Sci J Cons 70:270-283. doi: $10.1093 /$ icesjms/fss184

Campillo A (1992) Les pêcheries françaises de Méditerranée: synthèse des connaissances. Rapp Internes Dir Ressources Vivantes L'ifremer. p239.

Cardinale M, Casini M, Arrhenius F, Håkansson N (2003) Diel spatial distribution and feeding activity of herring (Clupea harengus) and sprat (Sprattus sprattus) in the Baltic Sea. Aquat Living Resour 16:283-292. doi: 10.1016/S09907440(03)00007-X

Checkley D, Alheit J, Oozeki Y, Roy C (2009) Climate Change and Small Pelagic Fish. Cambridge University Press, New York, US. p393.

Costalago D, Tecchio S, Palomera I, et al. (2011) Ecological understanding for fishery management: Condition and growth of anchovy late larvae during different seasons in the Northwestern Mediterranean. Estuar Coast Shelf Sci 93:350-358. doi: 10.1016/j.ecss.2011.05.005

Le Cren ED (1951) The Length-Weight Relationship and Seasonal Cycle in Gonad Weight and Condition in the Perch (Perca fluviatilis). J Anim Ecol 20:201-219. doi: 10.2307/1540 
Cury P, Bakun A, Crawford RJM, et al. (2000) Small pelagics in upwelling systems: patterns of interaction and structural changes in "wasp-waist" ecosystems. Ices J Mar Sci J Cons 57:603-618. doi: 10.1006/jmsc.2000.0712

Daskalov GM (2002) Overfishing drives a trophic cascade in the Black Sea. Mar Ecol Prog Ser 225:53-63. doi: $10.3354 /$ meps 225053

Demaneche S, Merrien C, Berthou P, Lespagnol P (2009) Rapport R3, Méditerranée continentale, échantillonnage des marées au débarquement. Méthode d'élévation et évaluation des captures et de l'effort de pêche des flottilles de la façade Méditerranée continentale sur la période 2007-2008. p217.

Doray M, Masse J, Petitgas P (2010) Pelagic fish stock assessment by acoustic methods at Ifremer. p18.

European Commission (2008) Establishing a framework for community action in the field of marine environmental policy (Marine Strategy Framework Directive). 2008/56/EC: 40.

FAO (2014) GFCM Capture Production (online query). Accessed 1 Aug 2013

Fraley C, Raftery EA, Murphy TB, Scrucca L (2013) mclust: Normal Mixture Modeling for Model-Based Clustering, Classification, and Density Estimation.

Froese R (2006) Cube law, condition factor and weight-length relationships: history, meta-analysis and recommendations. J Appl Ichthyol 22:241-253.

Frühwirth-Schnatter S (2008) MATLAB package bayesf.

Furnestin J (1948) OBSERVATIONS SUR LE SPRAT (Clupea Sprattus Linne ) DES COTES MERIDIONALES DE FRANCE (Atlantique et Méditerranée). Rev Trav Inst Pech Marit 14:39-69.

GFCM (2011) Report of the working group on stock assessment of small pelagic species. p46.

GFCM (2012) Report of the working group on stock assessment of small pelagic species. p258.

Grün B, Leisch F (2013) flexmix: Flexible Mixture Modeling.

Harvell CD, Kim K, Burkholder JM, et al. (1999) Emerging Marine Diseases--Climate Links and Anthropogenic Factors. Science 285:1505-1510. doi: 10.1126/science.285.5433.1505

Hunt L, Jorgensen M (1999) Mixture Model Clustering Using the Multimix Program. Aust New Zealand J Stat 41:154-171. doi: $10.1111 / 1467-842 X .00071$

Jakob EM, Marshall SD, Uetz GW (1996) Estimating Fitness: A Comparison of Body Condition Indices. Oikos 77:61-67. doi: $10.2307 / 3545585$

Jasra A, Holmes CC, Stephens DA (2005) Markov Chain Monte Carlo Methods and the Label Switching Problem in Bayesian Mixture Modelling. Stat Sci 20:50-67. doi: 10.1214/088342305000000016

Jones JB, Hyatt AD, Hine PM, et al. (1997) Australasian pilchard mortalities. World J Microbiol Biotechnol 13:383-392. doi: 10.1023/A:1018568031621 
Kada O, Abdellaoui S, Najih M, Nachite D (2010) Estimation de la croissance de la sardine (Sardina pilchardus Walb., 1792) de la région centro-orientale de la Méditerranée marocaine à l'aide de l'étude des otolithes. Bull L'institut Sci 32:13-15.

Laslett GM, Eveson JP, Polacheck T (2004) Fitting growth models to length frequency data. Ices J Mar Sci J Cons 61:218-230. doi: 10.1016/j.icesjms.2003.12.006

Lee JY (1961) La sardine du golfe du lion (Sardina pilchardus sardina REGAN). Rev Trav Inst Pech Marit 25:418-513.

Lee JY, Juge C (1965) Observations morphologiques et biologiques sur anchois (Engraulis encrasicolus) du golfe du Lion. Comm Int Pour Explor Sci Méditerranée Rapp P-V Réun 18:221-224.

Macdonald P, Du J (2012) mixdist: Finite Mixture Distribution Models.

MEDITS working group (2012) MEDITS. International bottom trawl survey in the Mediterranean. Instruction manual. Version 6. 93p.

Millán M (1999) Reproductive characteristics and condition status of anchovy Engraulis encrasicolus L. from the Bay of Cadiz (SW Spain). Fish Res 41:73-86. doi: 10.1016/S0165-7836(99)00010-7

Morales-Nin B, Pertierra JP (1990) Growth rates of the anchovy Engraulis encrasicolus and the sardine Sardina pilchardus in the Northwestern Mediterranean Sea. Mar Biol 107:349-356. doi: 10.1007/BF01319836

Nicolle A, Garreau P, Liorzou B (2009) Modelling for anchovy recruitment studies in the Gulf of Lions (Western Mediterranean Sea). Ocean Dyn 59:953-968. doi: 10.1007/s10236-009-0221-6

Oli MK, Dobson S (2003) The Relative Importance of Life-History Variables to Population Growth Rate in Mammals: Cole's Prediction Revisited. Am Nat 161:422-440.

Palomera I, Olivar MP, Salat J, et al. (2007) Small pelagic fish in the NW Mediterranean Sea: An ecological review. Prog Ocean 74:377-396. doi: 10.1016/j.pocean.2007.04.012

Pertierra JP, Morales-Nin B (1989) Sardine growth in the Catalan Sea (NW Mediterranean) determined by means of otolith interpretation and length frequency data. Sci Mar 53:821-826.

Pešić A, Đurović M, Joksimović A, et al. (2010) Some reproductive patterns of the sardine, Sardina pilchardus (Walb, 1792), in Boka kotorska Bay (Montenegro, southern Adriatic Sea). Acta Adriat 51:159-168.

Planque B, Fromentin J-M, Cury P, et al. (2010) How does fishing alter marine populations and ecosystems sensitivity to climate? J Mar Syst 79:403-417. doi: 10.1016/j.jmarsys.2008.12.018

Plounevez S, Champalbert G (2000) Diet, feeding behaviour and trophic activity of the anchovy (Engraulis encrasicolus L.) in the Gulf of Lions (Mediterranean Sea). Ocean Acta 23:175-192. doi: 10.1016/S0399-1784(00)00120-1

R core team (2013) R: A language and environment for statistical computing. R Foundation for Statistical Computing. Vienna, Austria

Rice J (1995) Food web theory, marine food webs and what climate changes may do to northern marine fish populations. In: Beamish RJ (ed) Clim. Change North. Fish Popul. Canadian Special Publications of Fisheries and Aquatic Sciences, pp 561568 
Ricker WE (1975) Computation and interpretation of biological statistics of fish populations. Bull Fish Res Board Can 191:1382.

Shannon L, Cury PM, Jarre A (2000) Modelling effects of fishing in the Southern Benguela ecosystem. Ices J Mar Sci J Cons 57:720-722. doi: 10.1006/jmsc.2000.0716

Sinclair M, Iles TD (1989) Population regulation and speciation in the oceans. Ices J Mar Sci 45:165-175. doi: 10.1093/icesjms/45.2.165

Sinovčić G, Keč VČ, Zorica B (2008) Population structure, size at maturity and condition of sardine, Sardina pilchardus (Walb., 1792), in the nursery ground of the eastern Adriatic Sea (Krka River Estuary, Croatia). Estuar Coast Shelf Sci 76:739744. doi: 10.1016/j.ecss.2007.07.037

Stahl JT, Oli MK (2006) Relative importance of avian life-history variables to population growth rate. Ecol Model 198:23-39.

Stan Development Team (2013) Stan Modeling Language User's Guide and Reference Manual, Version 1.3.

Stephens M (2000) Dealing with label switching in mixture models. J R Stat Soc Ser B Stat Methodol 62:795-809. doi: $10.1111 / 1467-9868.00265$

Tomlinson PK (1971) NORMSEP: Normal distribution separation. Comput. Program Fish Stock Assess.

Tugores MP, Iglesias M, Díaz N, et al. (2010) Latitudinal and interannual distribution of the European anchovy (Engraulis encrasicolus) and sardine (Sardina pilchardus) in the western Mediterranean, and sampling uncertainty in abundance estimates. Ices J Mar Sci J Cons 67:1574-1586. doi: 10.1093/icesjms/fsq057

Uriarte A, Pouzet P, Villamor B (1996) Bay of Biscay and Ibero Atlantic anchovy populations and their fisheries. Sci Mar 60:237-255.

Voulgaridou P, Stergiou KI (2003) Trends in various biological parameters of the European sardine, Sardina pilchardus (Walbaum, 1792), in the Eastern Mediterranean Sea. Sci Mar 67:269-280. doi: 10.3989/scimar.2003.67s1269

Zar JH (1999) Biostatistical analysis, 5th ed. Pearson Prentice-Hall, New York, US 
Fig. 1 Trend in total abundance (number) and biomass (tonnes) of anchovy, sardine and sprat in the Gulf of Lions. Data are from acoustic surveys (July)

Fig. 2 Evolution of the mean relative condition index per year for anchovy, sardine and sprat with the standard deviation. $\mathrm{N}$ is the number of data points used (i.e. the number of size classes of a given year for which weight data was available, over all trawls) and $n$, the number of fish measured

Fig. 3 Half-violin plots showing the change in size distribution of all three species over the studied period (years with less than 10 individuals measured were removed)

Fig. 4 Growth of anchovy and sardine per year obtained from otolith readings. Periods with a different growth rate are used as priors for the mixture models and are indicated with a different colour family. Because these periods differ for anchovy and sardine, years are not always indicated with the same colour for both species. Points indicate outliers (values more than 1.5 times the length of the box away from the box quantiles). Boxplots for age 0 anchovy were removed because of doubtful values, as well as boxplots based on less than five samples

Fig. 5 Evolution of the mean length per age (upper row) and the percentage of the population belonging to each age category (lower row) resulting from the mixture models

Fig. 6 PCA (without time lag) for anchovy and sardine showing the relative importance of 5 variables to explain the year-toyear variance, with the variance explained by each axis between brackets. No abundance data was available for the years 1992, 1994 and 2012, so they were excluded from the analyses 

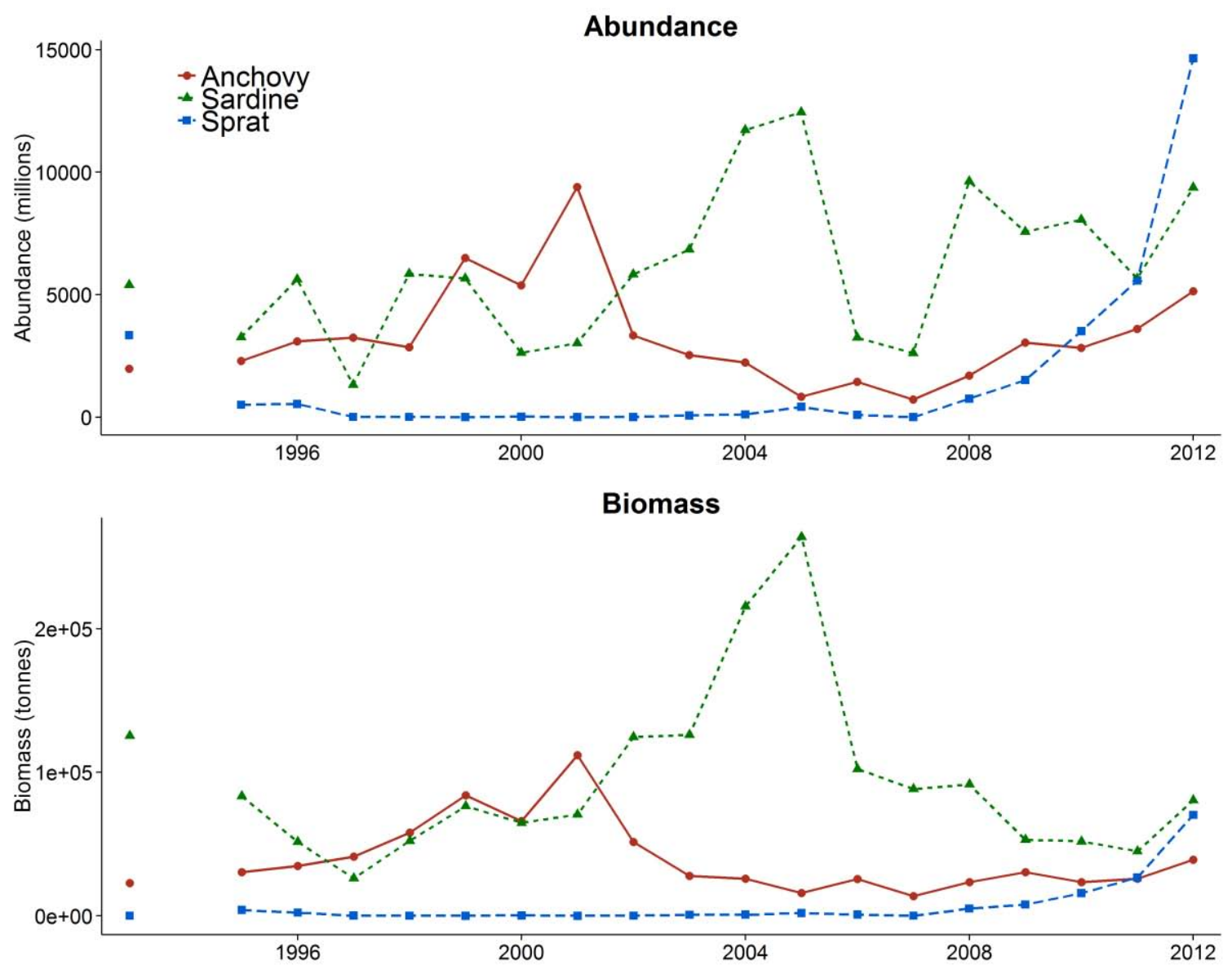
Anchovy
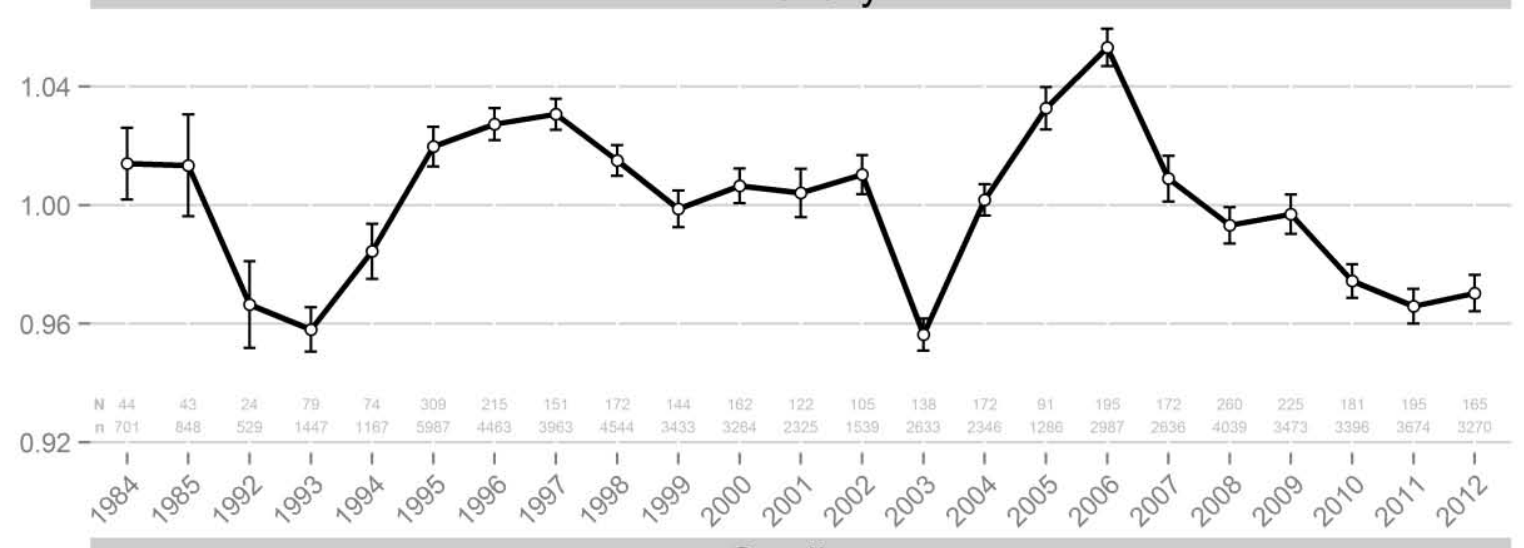

Sardine

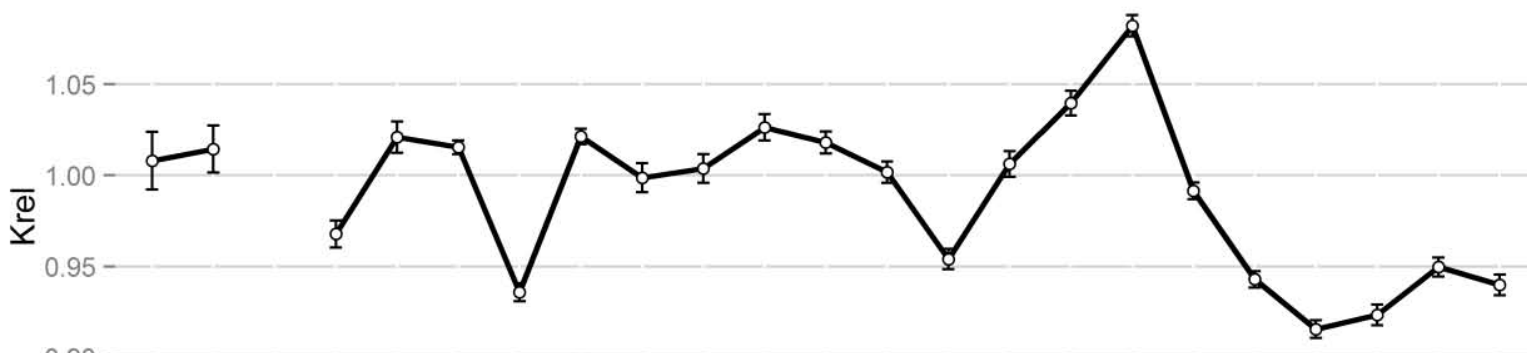

0.90

565

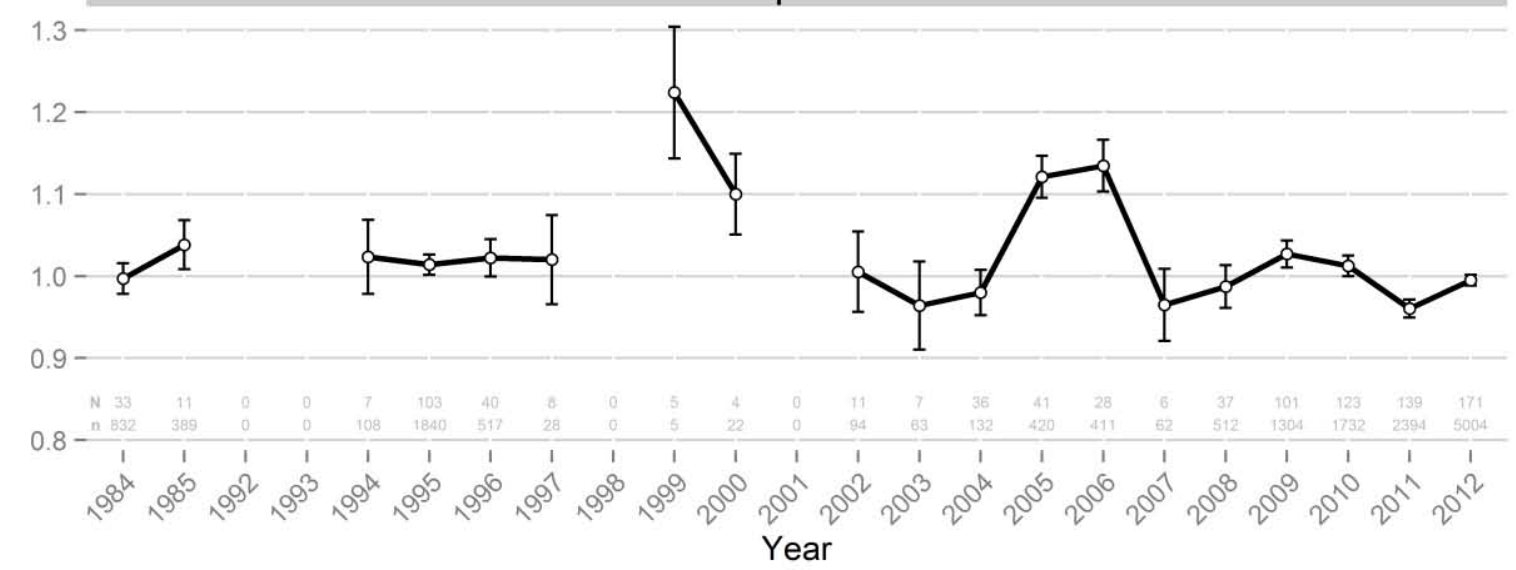

566 Fig. 2

20 


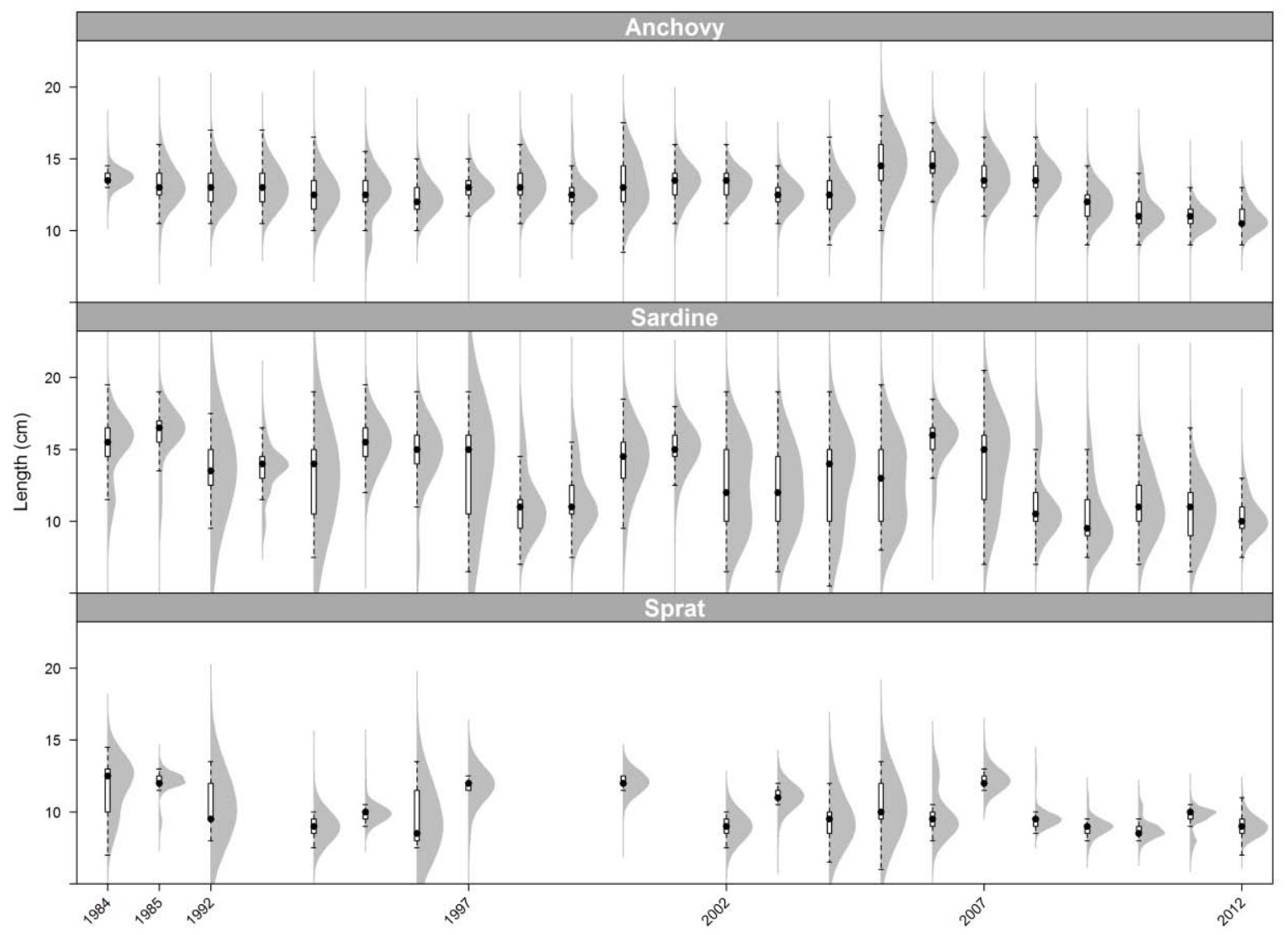

567

Fig. 3 


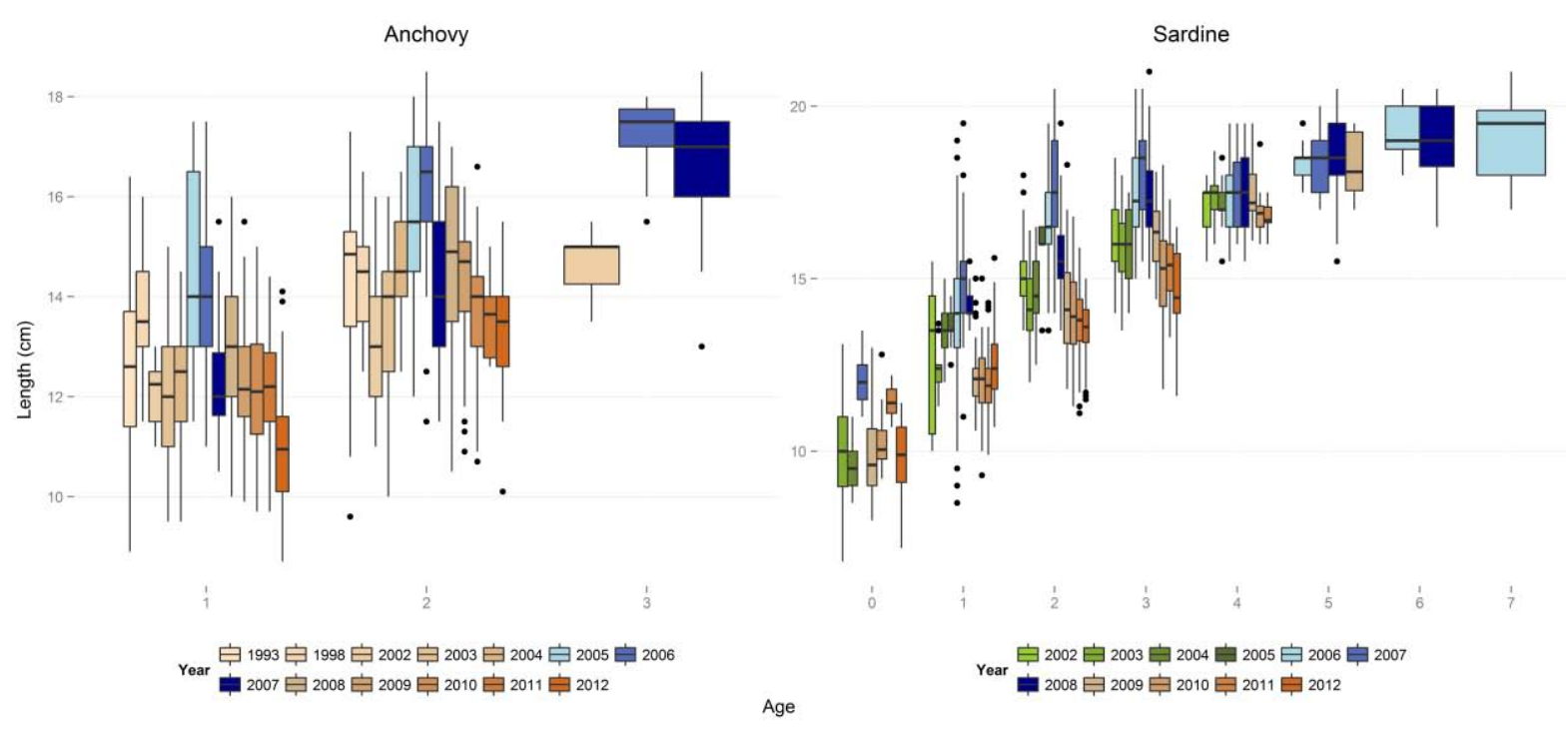

Fig. 4 

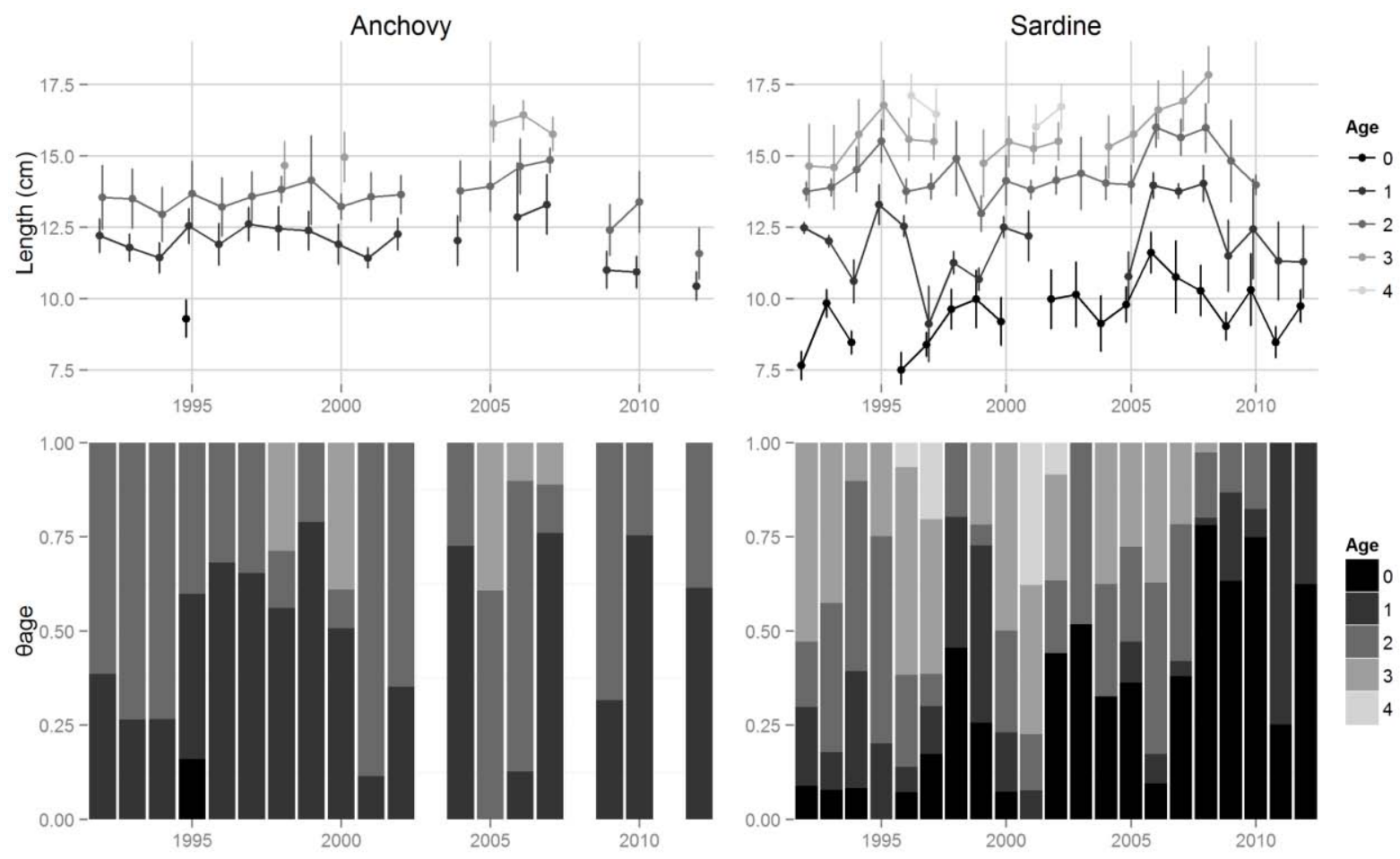

571

572

Fig. 5 

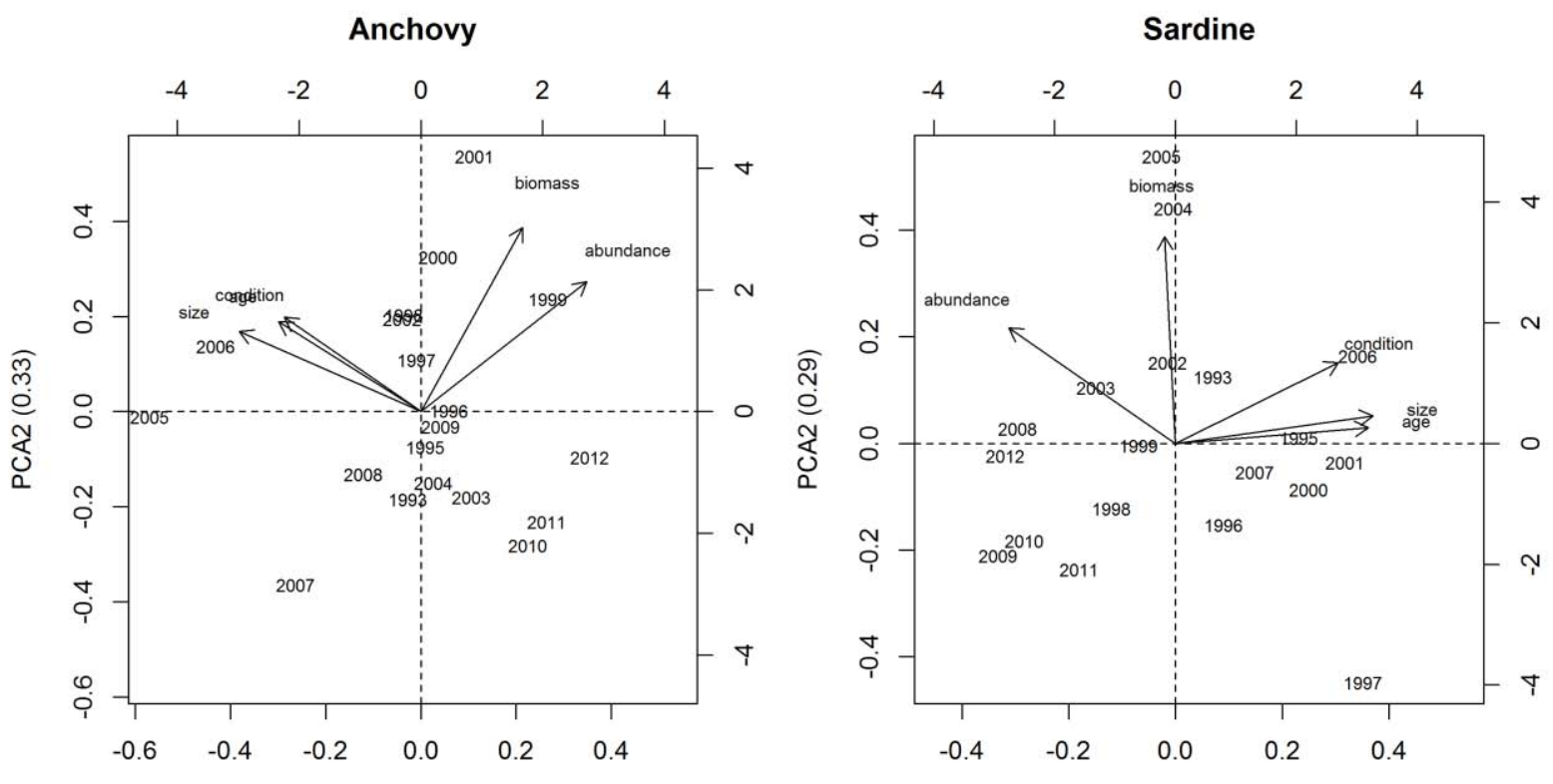

$574 \quad$ Fig. 6 


\section{Tables}

577 Table 1 Estimation of the Von Bertalanffy growth curve parameters and the phi-index for sardine during the following

578 periods: 2009-2012 (slow), 2002-2005 (intermediate), 2006-2008 (fast). All parameters are significant $(p<0.001)$.

\begin{tabular}{llllll}
\hline Species & Period & L $\infty$ & K & t0 & $\boldsymbol{\phi}^{\prime}$ \\
\hline Sardine & Slow & 33.57 & 0.09 & -4.1 & 2.01 \\
& Interm. & 18.38 & 0.45 & -1.73 & 2.18 \\
& Fast & 18.88 & 0.56 & -1.64 & 2.30 \\
\hline
\end{tabular}

579 